\title{
Spectroscopic investigation of polyaniline co poly meta amino benzene sulfonic acid
}

\author{
Jayanta K Ray* and Leena Bhowmik \\ Department of Chemistry, Indian Institute of Technology, \\ Kharagpur - 721302 INDIA
}

\begin{abstract}
Similar to metals, conducting polymers possess an extraordinary ability to conduct electricity due to their intrinsic properties. There has been considerable focus on the synthesis and development of such materials for a wide variety of applications. In this regard, polyaniline and its derivatives have versatile applications including use as active electronic material, fabrication of modified electrode, sensors, in secondary batteries and in microelectronic and electrochromic device. Introduction of potential polymers like PAN and PPY or PTF as conductive co-polymer, interpenetrating network or blends would be a challenging step towards the preparation of novel and cheap material with modified antistatic properties. In this work we used poly (m-amino benzene sulfonic acid) and poly aniline for the preparation of composite. Aniline and m-amino benzene sulfonic acid can be fast polymerized in water to yield conducting nano composites. The composites were easily water dispersable and showed prolonged stability.
\end{abstract}

\section{Introduction}

It is highly interesting to note that conducting polymers have strong ability to conduct electric current like conventional metals provided they compromise with other properties. During the last two decades, conducting polymer has received considerable research attention owing to its unique and useful properties. The synthesis and development of conducting polymers with the potential of replacing the expensive and rapidly depleting metal reserve have been one of the marvels of polymer chemistry ${ }^{1-4}$. Thus, the lightness 
of weight, easy processability and resistance against corrosion of organic polymer have led to many applications causing replacement of metals or to the creation of organic materials. Most of them, however, remain laboratory curiosities, but with tremendous potential for future scientific and technological development. The factors controlling the variation of conductivities over a wide range are mainly mode of synthesis, oxidant, reaction conditions, $\mathrm{pH}$, time, nature of dopants and doping level etc. Among these organic polymers, polyanilines, polypyrrole, polythiophene etc have attracted special attention due to its high stability towards air and moisture, high electrical conductivity and unique redox properties. However, polyanilines are almost insoluble in common organic solvents especially in doped form, which causes difficulties in determination of molecular structure and restricts them to practical use. The technique has been applied in the more diverse field of research to get better applicable materials ${ }^{5-22}$.

Polyaniline and its derivatives have versatile applications including use as active electronic material, fabrication of modified electrode, sensors, in secondary batteries and in microelectronic and electrochromic device. To improve the processability thermal and environmental stability and to induce novel electronic and electrochemical properties substituted poly anilines being developed. ${ }^{23-26}$ Poly nuclear aromatic amines are new class of conducting materials of $\pi$ - conjugated aromatic organic polymers e.g Poly (phenelene), Polyaniline, Polythiophene, Poly pyrrole. ${ }^{27-30}$ Of late considerable research attention has been paid to the preparation and evaluation of aqueous colloidal dispersion of different conducting polymer ${ }^{31-40}$. Introduction of potential polymer like PAN and PPY or PTF as conductive co-polymer, interpenetrating network or blends would be a challenging step towards the preparation of novel and cheap material with modified antistatic and electromagnetic properties ${ }^{41-47}$. The research thus appears to be of wide scope and further work in this series will be directed to this end.

Such types of composite are readily prepared by synthesizing the conducting polymer in presence of another conducting polymer commonly in aqueous medium. The monomers most widely used in this study are pyrrole (Py) and aniline (ANI). In this work we used poly ( $\mathrm{m}$-amino benzene sulfonic acid) and poly aniline for the preparation of composite. Aniline and m-amino benzene sulfonic acid can be fast polymerized in water 
by $\mathrm{FeCl}_{3}$ or $(\mathrm{NH} 4)_{2} \mathrm{~S}_{2} \mathrm{O}_{8}$ to yield conducting nano composites. The composite can be dispersed in a stable aqueous dispersion medium.

\section{Experimental}

\section{Materials}

Aniline was purchased from SD chemicals (India). It was doubly distilled with Zn dust prior to polymerization. The monomer m-amino benzene sulfonic acid was purchased from SRL (India) and used without further purification. Ammonium persulfate from S.D. fine chemicals was used as oxidant without any purification. $\mathrm{HCl}$ purchased from SRL chemicals. For polymerization, conc. $\mathrm{HCl}(35.4 \%$, AR, sp. gr.1.18) was diluted to $1 \mathrm{M}$ solution.

\section{Polyaminobenzene sulfonic acid synthesis and composite preparation}

Poly (m-amino benzene sulfonic acid) (PABS) was synthesized by chemical oxidation in protic acid medium, using aniline as initiator (15 mole \%). m- Amino benzene sulfonic acid normally does not participate in homopolymerization possibly due to deactivating and bulky $\mathrm{SO}_{3} \mathrm{H}$ substituent in the phenyl system ${ }^{48}$. [Poly (m- amino benzene sulfonic)] The preparation procedure was mentioned else where ${ }^{49}$. (PABS) acid was water soluble conducting polymer. Previously prepared a known quantity of PABS was placed in stoppered pyrex tube and dissolved in distilled water. After that measured quantity of aniline dissolved in $1 \mathrm{M} \mathrm{HCl}$ solution added dropwise to the reaction vessel. Stirring was done for 30 mins. After that a solution of $\left(\mathrm{NH}_{4} \mathrm{~S}_{2} \mathrm{O}_{8}\right)$ in $\mathrm{HCl}$ was added to the solution over a period of 30-40 min at $0{ }^{0} \mathrm{C}$. The reaction mixture was stirred again for $3 \mathrm{~h}$. Then total contents of flask were centrifuged at 18,500 rpm and centrifugate was separated from the residue. This process was repeated at least four times to remove adhered $\left(\mathrm{NH}_{4} \mathrm{~S}_{2} \mathrm{O}_{8}\right)$. This procedure was expected to dissolve out all surface adsorbed ammonium persulfate. Table 1 summarizes the results of the preparations. The separated black mass was washed by methanol and finally dried at $60{ }^{\circ} \mathrm{C}$ for $5 \mathrm{~h}$ under vaccum.

Table 1 Experimental details for the preparation of the composite

\begin{tabular}{|l|l|l|ll|l|}
\hline Entry & Weight (g) in feed & Time & $\%$ Polymer & Conductivity \\
\hline
\end{tabular}




\begin{tabular}{|l|c|c|c|c|c|}
\hline No & PABS & PAN & (h) & & (S/cm) \\
\hline 1. & 0.15 & 0.10 & 4 & 68 & $1.9 \times 10^{-4}$ \\
2 & 0.15 & 0.15 & 4 & 71 & $1.8 \times 10^{-4}$ \\
3. & 0.15 & 0.20 & 4 & 74 & $2.4 \times 10^{-4}$ \\
4 & 0.15 & 0.25 & 4 & 75 & $2.5 \times 10^{-4}$ \\
5 & 0.20 & 0.20 & 4 & 71 & $2.9 \times 10^{-4}$ \\
6 & 0.25 & 0.20 & 4 & 68 & $2.1 \times 10^{-4}$ \\
7 & 0.30 & 0.20 & 4 & 66 & $2.3 \times 10^{-4}$ \\
8 & 0.35 & 0.20 & 4 & 62 & $2.2 \times 10^{-4}$ \\
& & & & & \\
\hline
\end{tabular}

\section{Viscosity measurement}

Intrinsic viscosities were determined in $96 \%$ sulfuric acid at $30{ }^{0} \mathrm{C}$ using polymer concentration between 0.05 and $0.1 \mathrm{~g} / \mathrm{dl}$ with an ubbelohde capillary viscometer. As the exact molecular weight distribution could not be determined due to the unavailability of necessary experimental facilities (including GPC) a qualitative assessment of the molecular weight of prepared polymer relative to polyaniline was effect, based upon the measurement of intrinsic viscosities $\left(\eta_{\text {int }}\right)$ of these polymers.

\section{D.C. electrical conductivity}

Conductivity measurements were made by two-probe technique using a Philips RP 9500 Bridges and Keithley 177 Micro voltmeter at room temperature. The sample was in the form of compacted disk pellets, $0.3 \mathrm{~cm}$ in diameter and different thickness. Four measurements were used to assure constant resistance for each of sample.

\section{Infrared spectroscopic analysis}

The IR spectra of polymer in $\mathrm{KBr}$ pellets were recorded on a Perkin-Elmer (model-833) infrared spectrometer by optically zero balancing in the range $400-4000 \mathrm{~cm}^{-1}$ using 2-4 mg dry powder.

\section{Thermal stability}


Differential thermal analysis and thermogravimetric analysis of the above composites were carried out using Shimadzu DT-40 unit under static air. A heating rate $10{ }^{0} \mathrm{C} / \mathrm{min}$ was used

\section{Scanning electron microscopic analysis}

Scanning electron micrographs of the polymer samples were taken on cam scans $2 \mathrm{DV}$ units with variation of magnification. Powder samples of the polymers were deposited on the stubs by ultrasonic dispersion and then gold coated for studying the morphology of the samples.

\section{Transmission electron microscopic analysis}

The particle size of the composite was determined by transmission electron microscopy using Hitachi 600 instrument.

\section{Results and Discussion}

Polyaminobenzene sulfonic acid synthesis and composite preparation.

The addition of $\left(\mathrm{NH}_{4} \mathrm{~S}_{2} \mathrm{O}_{4}\right)$ solution to monomer solution was accompanied by a gradual color change of the system from greenish blue to black, indicating formation of polyaniline. In general, the formation composite increases with increase aniline/ PABS ratio. Conversely with increase in PABS concentration, the total conversion to the composite gradually decreases because it merely acts as a diluent of $\left(\mathrm{NH}_{4} \mathrm{~S}_{2} \mathrm{O}_{8}\right)$ and reduces its effective concentration as initiator. ${ }^{50,51}$

\section{Viscosity measurement}

Table 2 Solubility and Viscosity data of Polymer

\begin{tabular}{|l|c|l|}
\hline Solvent & Composite & $\begin{array}{l}\eta_{\text {ins at } 30^{0}} \mathbf{C} \\
(\mathbf{d L} / \mathbf{g})\end{array}$ \\
\hline & & \\
$\mathrm{NH}_{4} \mathrm{OH}$ & $\mathrm{Ss}$ & \\
$\mathrm{H}_{2} \mathrm{O}$ & $\mathrm{I}$ & \\
$\mathrm{C}_{6} \mathrm{H}_{6}$ & $\mathrm{Ss}$ & \\
$\mathrm{THF}$ & $\mathrm{ms}$ & \\
$\mathrm{DMF}$ & $\mathrm{ms}$ & \\
\hline
\end{tabular}




\begin{tabular}{|l|c|c|}
\hline DMSO & $\mathrm{ms}$ & \\
$\mathrm{H}_{2} \mathrm{SO}_{4}$ & $\mathrm{~s}$ & 0.35 \\
& & \\
\hline
\end{tabular}

All the polymer powder was completely soluble in polar solvent like NMP and DMSO. All the composites are soluble in conc. $\mathrm{H}_{2} \mathrm{SO}_{4}(96 \%)$. So the viscosity measurements were carried out in $\mathrm{H}_{2} \mathrm{SO}_{4}$. The intrinsic viscosity data qualitatively indicate that the newly formed composites have quite low molecular weight compared to polyaniline $(0.57$ $\mathrm{dl} / \mathrm{g}$ ), which showed much higher viscosity. This was expected because the steric effects and also the deactivating influence of the substitute retard chain growth.

\section{C. electrical conductivity}

The conductivity data of Table 1 revealed that PABS-PAN composite exhibited a dc conductivity of the order $1.3 \times 10^{-4} \mathrm{~S} / \mathrm{cm}$, which was quite improved from PABS $(8.5 \times 10$

${ }^{-5} \mathrm{~S} / \mathrm{cm}$ ). The sulfonic acid groups substituted on the benzene rings caused an increase in band gap and decreased the conductivity due to their strong electron withdrawing nature and high substitution resulting in large steric strain.

\section{Infrared spectroscopic analysis}

The representative infrared spectra of the polymer composites are shown in Figure 1. The bands appeared at $3400-3430 \mathrm{~cm}^{-1}$ were assigned to characteristic $\mathrm{N}-\mathrm{H}$ stretching vibration for amine/ imine nitrogen.

Table 3 Characteristic infrared stretching vibration

\begin{tabular}{|l|l|l|l|l|l|}
\hline \multirow{2}{*}{ Sample } & \multicolumn{5}{|c|}{ Stretching Modes (cm-1) } \\
\cline { 2 - 6 } & Quinoid & Benzoid & $\mathrm{C}-\mathrm{N}$ & $\mathrm{SO}_{2}$ & $\mathrm{C}-\mathrm{S}$ \\
\hline 1. & 1586 & 1490 & 1123 & 1020 & 613 \\
2 & 1595 & 1595 & 1123 & 1030 & 619 \\
3 & 1580 & 1489 & 1124 & 1029 & 612 \\
4 & 1576 & 1488 & 1124 & 1012 & 612 \\
5 & 1584 & 1494 & 1123 & 1016 & 612 \\
& & & & & \\
\hline
\end{tabular}


The characteristic quinoid and benzoid stretching bands appeared in PAN at 1589 $\mathrm{cm}^{-1}$ and $1498 \mathrm{~cm}^{-1}$. The curve exhibited a characteristic strong Quinoid absorption at $1586 \mathrm{~cm}^{-1}$ and weak benzenoid vibration at $1515 \mathrm{~cm}^{-1}$. The IR spectra showed that with increasing proportion of aniline both quinoid and benzoid stretching shift towards lower frequency. Symmetric stretching vibration (PABS) of $\mathrm{SO}_{2}$ displayed at 1170 and 1028 $\mathrm{cm}^{-1}$ and peaks at 693 and $616 \mathrm{~cm}^{-1}$ are assigned to the S-O and C-S stretching modes. The asymmetric stretching of $\mathrm{SO}_{2}\left(1300-1320 \mathrm{~cm}^{-1}\right)$ may overlap with characteristic C-N bond vibration $\left(1307 \mathrm{~cm}^{-1}\right)$ of PAN. The relative intensity of benzoid to quinoid absorption peak cannot be used here as an index of oxidation, on account of the difference in position asymmetric $\mathrm{S}=\mathrm{O}$ stretching of PABS in this region and their possible overlap with other peaks. The absorption at $875-883 \mathrm{~cm}^{-1}$ and $792-798 \mathrm{~cm}^{-1}$ for C-H out of plane bending vibration.

\section{Thermal stability}

Figure $2 \mathrm{a}, 2 \mathrm{~b}$ and $.2 \mathrm{c}$ represented typical weight loss versus temperature data poly (mamino benzene sulfonic acid), Polyaniline and composite respectively. Thermal analysis pattern showed that the relative stability of the polymer composite, poly aniline and poly amino benzene sulfonic acid. First two stages of weight loss can be attributed to the expulsion of free and bonded water molecule and the morphological changes of molecule. The thermogram was exothermic over the entire range of analysis.

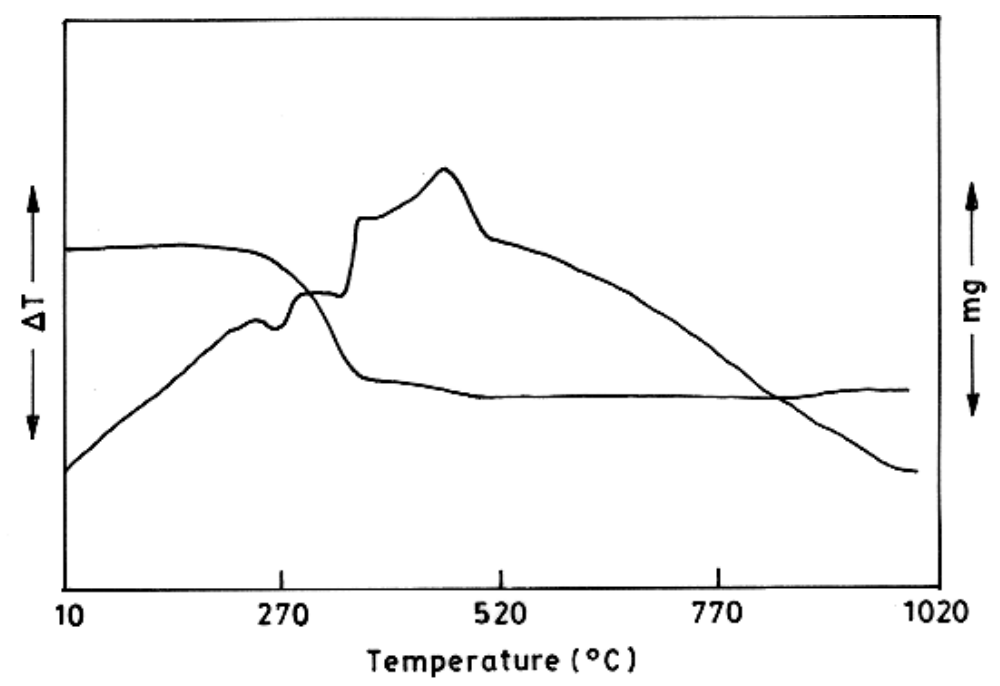


Figure 2a. TGA/ DTA diagram of $\mathrm{m}$ - amino benzene sulfonic acid.

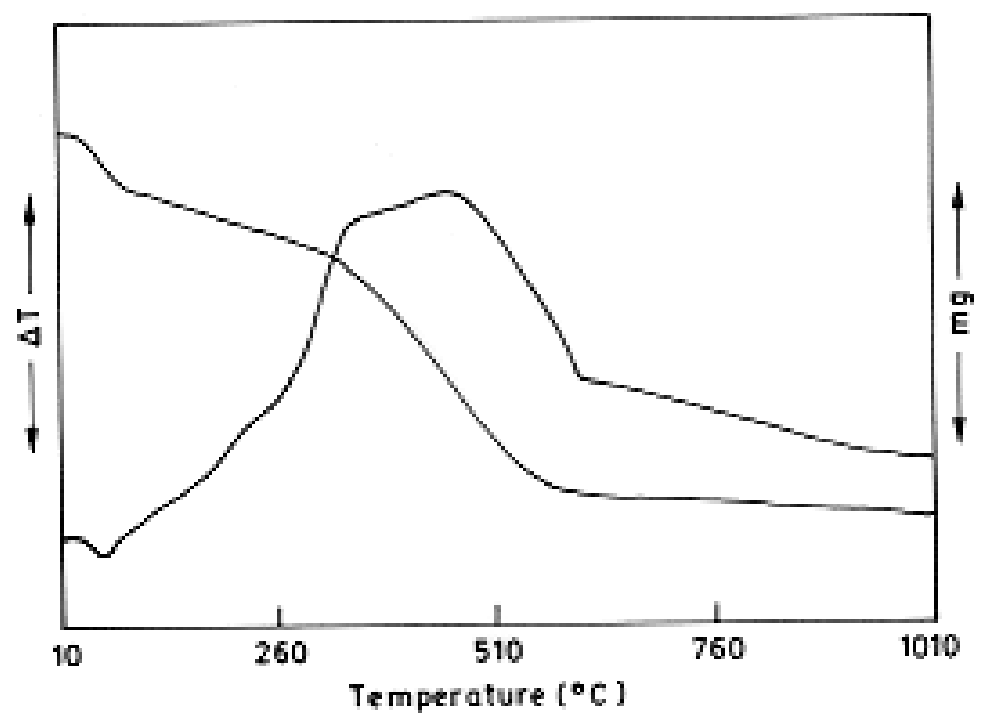

Figure 2b. TGA/ DTA diagram of poly aniline.

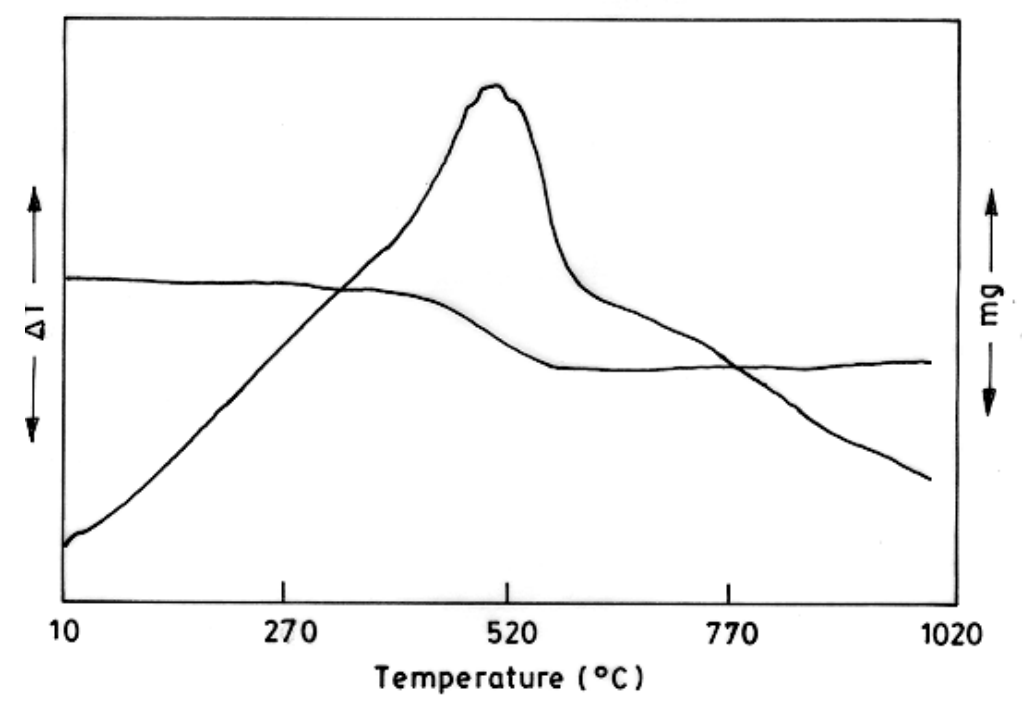

Figure $2 \mathrm{c}$ Thermal diagram of composite 
Table 4 Thermal analysis diagram of polymer composite

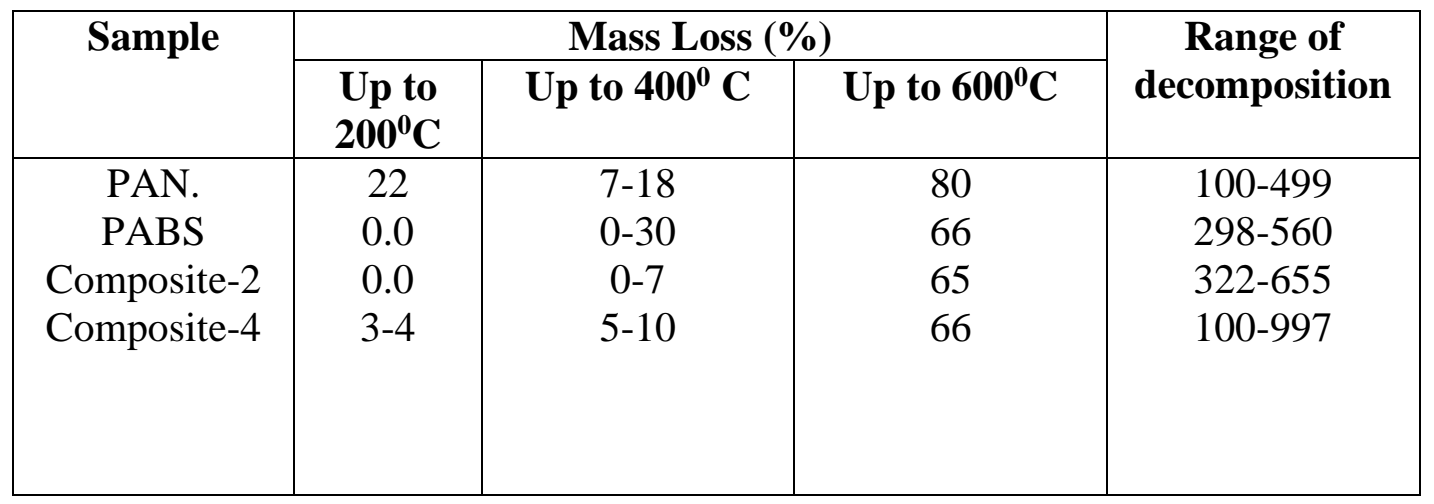

Such exothermic behaviour of the composite has been attributed to cross linking of polymer chain and rearrangement and degradation of side chain. And the final weight loss (Table 4) was due to the thermal degradation of the polymer backbone. The thermal analysis data did not indicate any pronounced stability difference between two composites (having different proportion of two polymers). Though they were more stable than that of PAN and PABS as indicated by their decomposition temperatures. The PABS-PAN composite showed maximum thermal stability. It exhibited highest decomposition temperature and low weight loss prior to the final degradation. The final stage of thermal degradation took place in different stages. The thermal changes prior to final decomposition were likely to be a composite of a number of events including loss of water (Endothermic), H-bonding (Exothermic) bond rupture, cross linking, rearrangement and degradation of side chains (exothermic). The significant thermal stability of the composite may be rationalized. The experimental results at the present level however do not warrant a detailed explanation.

Scanning electron microscopic analysis
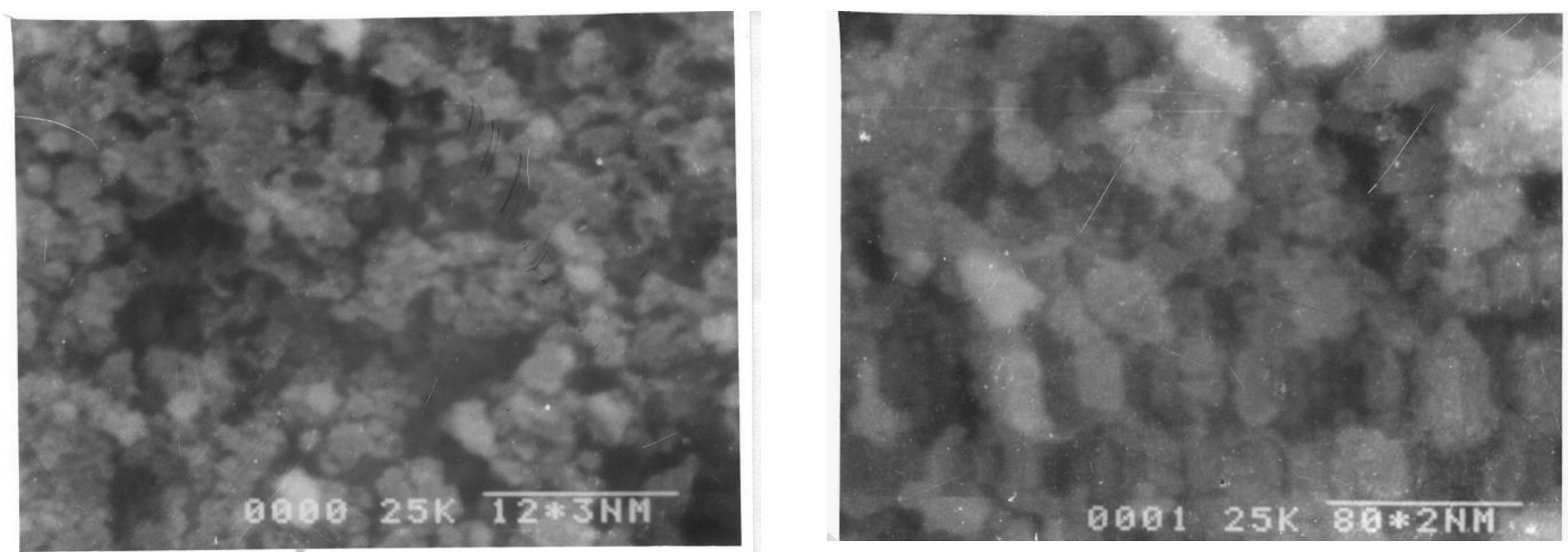


\section{Figure. 3 SEM micrograph of composites}

The SEM photographs (Figure .3) showed typical features for above-mentioned composites. They were mainly composed of irregularly arranged rhombohedral blocks with sharp edge and interspersed with smaller granular form. Simultaneously the structure looks more porous.

Transmission electron microscopic analysis

Figure 4 presented two typical TEM micrographs of this composite. The lighter region in the background of the TEM picture was due to polyaniline particle and the darker region was due to poly ( $\mathrm{m}$-amino benzene sulfonic acid) particles. The average particle diameter for the composite as calculated from the TEM photographs was 70nm respectively.

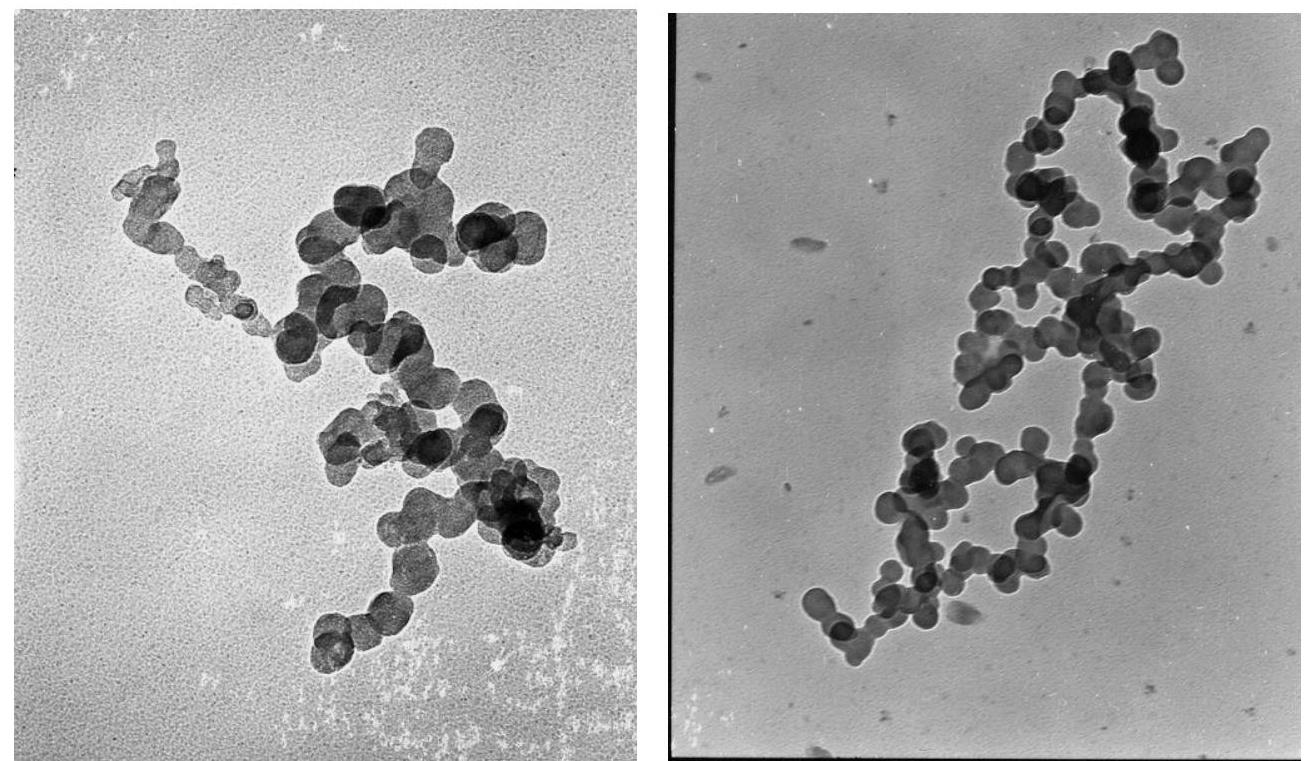


Figure 4. TEM picture of PABS-PAN composite

\section{Conclusion}

We present a simple method of preparation of polyaniline and poly a9am-amino benzene sulphonic acid) by oxidative polymerization protocol. Composites are consistent as per IR, DSC, SEM and TEM data.

\section{References}

1. Jayanta, R.; Leena, B., Preparation and Evaluation of Novel Bamboo-Polymer Composites. 2021.

2. Fleige, E.; Quadir, M. A.; Haag, R., Stimuli-responsive polymeric nanocarriers for the controlled transport of active compounds: Concepts and applications. Advanced Drug Delivery Reviews 2012, 64 (9), 866-884.

3. Jayanta, R.; Leena, B., Sol Gel Technique to Prepare Composite Material of Glass-Dye-Polymers. 2021.

4. Babak, K.; Torabi, M.; Foad, K.; Priyanka, R., Novel $\beta$-Cyclodextrin Functionalized Core-Shell Fe3O4 Magnetic Nanoparticles for the Removal of Toxic Metals from Water. 2021.

5. Ray, P.; Haideri, N.; Haque, I.; Mohammed, O.; Chakraborty, S.; Banerjee, S.; Quadir, M.; Brinker, A. E.; Banerjee, S. K., The Impact of Nanoparticles on the Immune System: A Gray Zone of Nanomedicine. Journal of Immunological Sciences 2021, 5 (1).

6. $\quad$ Ray, P.; Dutta, D.; Haque, I.; Nair, G.; Mohammed, J.; Parmer, M.; Kale, N.; Orr, M.; Jain, P.; Banerjee, S.; Reindl, K. M.; Mallik, S.; Kambhampati, S.; Banerjee, S. K.; Quadir, M., pH-Sensitive Nanodrug Carriers for Codelivery of ERK Inhibitor and Gemcitabine Enhance the Inhibition of Tumor Growth in Pancreatic Cancer. Molecular Pharmaceutics 2021, 18 (1), 87-100.

7. Ray, P.; Kale, N.; Quadir, M., New side chain design for $\mathrm{pH}$-responsive block copolymers for drug delivery. Colloids and Surfaces B: Biointerfaces 2021, 200, 111563. 
8. Clément, M.; Abdellah, I.; Ray, P.; Martini, C.; Coppel, Y.; Remita, H.; Lampre, I.; Huc, V., Synthesis and NMR study of trimethylphosphine gold(i)-appended calix[8] arenes as precursors of gold nanoparticles. Inorganic Chemistry Frontiers 2020.

9. Abdullah, C. S.; Ray, P.; Alam, S.; Kale, N.; Aishwarya, R.; Morshed, M.; Dutta, D.; Hudziak, C.; Banerjee, S. K.; Mallik, S.; Banerjee, S.; Bhuiyan, M. S.; Quadir, M., Chemical Architecture of Block Copolymers Differentially Abrogate Cardiotoxicity and Maintain the Anticancer Efficacy of Doxorubicin. Molecular Pharmaceutics 2020, 17 (12), 4676-4690.

10. Confeld, M. I.; Mamnoon, B.; Feng, L.; Jensen-Smith, H.; Ray, P.; Froberg, J.; Kim, J.; Hollingsworth, M. A.; Quadir, M.; Choi, Y.; Mallik, S., Targeting the tumor core: hypoxia-responsive nanoparticles for delivery of chemotherapy to pancreatic tumors. Molecular Pharmaceutics 2020.

11. Sarker, N. C.; Ray, P.; Pfau, C.; Kalavacharla, V.; Hossain, K.; Quadir, M., Development of Functional Nanomaterials from Wheat Bran Derived Arabinoxylan for Nucleic Acid Delivery. Journal of Agricultural and Food Chemistry 2020, 68 (15), 43674373.

12. Ray, P.; Nair, G.; Ghosh, A.; Banerjee, S.; Golovko, M. Y.; Banerjee, S. K.; Reindl, K. M.; Mallik, S.; Quadir, M., Microenvironment-sensing, nanocarrier-mediated delivery of combination chemotherapy for pancreatic cancer. Journal of Cell Communication and Signaling 2019.

13. Ray, P.; Alhalhooly, L.; Ghosh, A.; Choi, Y.; Banerjee, S.; Mallik, S.; Banerjee, S.; Quadir, M., Size-Transformable, Multifunctional Nanoparticles from Hyperbranched Polymers for Environment-Specific Therapeutic Delivery. ACS Biomaterials Science \& Engineering 2019, 5 (3), 1354-1365.

14. Ghosh, A.; Sarkar, S.; Ghosh, S.; Ray, P.; Quadir, M.; Banerjee, S. K.; Banerjee, S., Abstract 1234: Zoledronic acid-induced suppression of invasive phenotypes of pancreatic cancer cells is mediated through downregulation of CYR61/CCN1. Cancer Research 2019, 79 (13 Supplement), 1234.

15. Ray, P.; Clément, M.; Martini, C.; Abdellah, I.; Beaunier, P.; RodriguezLopez, J.-L.; Huc, V.; Remita, H.; Lampre, I., Stabilisation of small mono- and bimetallic gold-silver nanoparticles using calix[8]arene derivatives. New Journal of Chemistry 2018, 42 (17), 14128-14137.

16. Brahma, S.; Ray, P.; Singha, R.; Ray, J. K., Visible Colourimetric and Ratiometric Fluorescent Chemosensors for $\mathrm{Cu}$ (II) and $\mathrm{Ni}$ (II) Ions. Asian Journal of Chemistry 2016, 28 (5), 1035.

17. André, E.; Boutonnet, B.; Charles, P.; Martini, C.; Aguiar-Hualde, J. M.; Latil, S.; Guérineau, V.; Hammad, K.; Ray, P.; Guillot, R.; Huc, V., A New, Simple and Versatile Strategy for the Synthesis of Short Segments of Zigzag-Type Carbon Nanotubes. Chemistry 2016, 22 (9), 3105-14.

18. Singha, R.; Roy, S.; Nandi, S.; Ray, P.; Ray, J. K., Palladium-catalyzed one-pot Suzuki-Miyaura cross coupling followed by oxidative lactonization: a novel and efficient route for the one-pot synthesis of benzo[c]chromene-6-ones. Tetrahedron Letters 2013, 54 (7), 657-660.

19. Ray, D.; Nasima, Y.; Sajal, M. K.; Ray, P.; Urinda, S.; Anoop, A.; Ray, J. K., Palladium-Catalyzed Intramolecular Oxidative Heck Cyclization and Its Application 
toward a Synthesis of $( \pm)$ - $\beta$-Cuparenone Derivatives Supported by Computational Studies. Synthesis 2013, 45 (09), 1261-1269.

20. Ray, P.; Ferraro, M.; Haag, R.; Quadir, M., Dendritic Polyglycerol-Derived Nano-Architectures as Delivery Platforms of Gemcitabine for Pancreatic Cancer. Macromol Biosci 2019, 19 (7), e1900073.

21. Das, A.; Haque, I.; Ray, P.; Ghosh, A.; Dutta, D.; Quadir, M.; De, A.; Gunewardena, S.; Chatterjee, I.; Banerjee, S.; Weir, S.; Banerjee, S. K., CCN5 activation by free or encapsulated EGCG is required to render triple-negative breast cancer cell viability and tumor progression. Pharmacol Res Perspect 2021, 9 (2), e00753. 22. Ray, P.; Confeld, M.; Borowicz, P.; Wang, T.; Mallik, S.; Quadir, M., PEG-bpoly (carbonate)-derived nanocarrier platform with $\mathrm{pH}$-responsive properties for pancreatic cancer combination therapy. Colloids Surf B Biointerfaces 2018, 174, 126135.

23. Roy, B. C.; Gupta, M. D.; Bhoumik, L.; Ray, J. K., Spectroscopic investigation of water-soluble polyaniline copolymers. Synthetic Metals 2002, 130 (1), 27-33.

24. Brahma, S.; Ray, J. K., Halovinyl aldehydes: useful tools in organic synthesis. Tetrahedron 2008, 13 (64), 2883-2896.

25. Roy, B. C.; Gupta, M. D.; Bhowmik, L.; Ray, J. K., Studies on water soluble conducting polymer: Aniline initiated polymerization of $\mathrm{m}$-aminobenzene sulfonic acid. Synthetic Metals 1999, 100 (2), 233-236.

26. Banwell, M. G.; Jones, M. T.; Loong, D. T. J.; Lupton, D. W.; Pinkerton, D. M.; Ray, J. K.; Willis, A. C., A Pd[0]-catalyzed Ullmann cross-coupling/reductive cyclization approach to C-3 mono-alkylated oxindoles and related compounds. Tetrahedron 2010, 66 (47), 9252-9262.

27. Jana, R.; Chatterjee, I.; Samanta, S.; Ray, J. K., Novel and Rapid PalladiumAssisted $6 \pi$ Electrocyclic Reaction Affording 9,10-Dihydrophenanthrene and Its Analogues. Organic Letters 2008, 10 (21), 4795-4797.

28. Mal, S. K.; Ray, D.; Ray, J. K., Palladium-catalyzed tandem oxidative cyclization of 1-bromohexa-1,5-dien-3-ols: easy access to cyclopentenones. Tetrahedron Letters 2004, 45 (2), 277-279.

29. Kovacic, P.; Oziomek, J., p-Polyphenyl from Benzene-Lewis Acid CatalystOxidant. Reaction Scope and Investigation of the Benzene-Aluminum ChlorideCupric Chloride System1. The Journal of Organic Chemistry 1964, 29 (1), 100-104.

30. Some, S.; Dutta, B.; Ray, J. K., Synthesis of substituted benzene derivatives by homo- and hetero-coupling of 2-bromobenzaldehyde and bromovinylaldehydes followed by McMurry coupling. Tetrahedron Letters 2006, 47 (7), 1221-1224.

31. Ray, P.; Gidley, D.; Badding, J. V.; Lueking, A. D., UV and chemical modifications of polymer of Intrinsic Microporosity 1 to develop vibrational spectroscopic probes of surface chemistry and porosity. Microporous and Mesoporous Materials 2019, 277, 29-35.

32. Ray, J. K.; Singha, R.; Ray, D.; Ray, P.; Rao, D. Y.; Anoop, A., Palladiumcatalyzed expedient Heck annulations in 1-bromo-1,5-dien-3-ols: Exceptional formation of fused bicycles. Tetrahedron Letters 2019, 60 (13), 931-935.

33. Ray, P.; Xu, E.; Crespi, V. H.; Badding, J. V.; Lueking, A. D., In situ vibrational spectroscopy of adsorbed nitrogen in porous carbon materials. Physical Chemistry Chemical Physics 2018, 20 (22), 15411-15418. 
34. Ray, J. K.; Paul, S.; Ray, P.; Singha, R.; Rao, D. Y.; Nandi, S.; Anoop, A., Pdcatalyzed intramolecular sequential Heck cyclization and oxidation reactions: a facile pathway for the synthesis of substituted cycloheptenone evaluated using computational studies. New Journal of Chemistry 2017, 41 (1), 278-284.

35. Chaudhuri, S.; Maity, S.; Roy, M.; Ray, P.; Ray, J. K., A Vinyl Radical Cyclization Route to Hydroxycyclohexene Fused Carbocycles. Asian Journal of Chemistry 2016, 28 (1).

36. Ray, P.; Gray, J. L.; Badding, J. V.; Lueking, A. D., High-Pressure Reactivity of Triptycene Probed by Raman Spectroscopy. The Journal of Physical Chemistry B 2016, 120 (42), 11035-11042.

37. Ray, P., Interactions of nitrogen and hydrogen with various $1 \mathrm{D}$ and $3 \mathrm{D}$ carbon materials probed via in-situ vibrational spectroscopy. Ph. D. Thesis 2016.

38. Wang, C.-Y.; Ray, P.; Gong, Q.; Zhao, Y.; Li, J.; Lueking, A. D., Influence of gas packing and orientation on FTIR activity for $\mathrm{CO}$ chemisorption to the $\mathrm{Cu}$ paddlewheel. Physical Chemistry Chemical Physics 2015, 17 (40), 26766-26776.

39. Brahma, S.; Ray, P.; Ray, J. K., Synthesis of azirines containing aldehyde functionality and their utilization as synthetic tools for five membered oxazoles and isoxazoles (vol 45, pg 311, 2008). JOURNAL OF HETEROCYCLIC CHEMISTRY 2021.

40. Ray, P. Calixarenes and Nanoparticles: Synthesis, Properties and Applications. 2013.

41. Jana, R.; Samanta, S.; Ray, J. K., Substrate dependent intramolecular palladiumcatalysed cyclisation and subsequent $\beta-\mathrm{H}$ elimination or $\mathrm{C}-\mathrm{H}$ activation: a general method for the synthesis of fused pyran rings. Tetrahedron Letters 2008, 49 (5), 851-854.

42. Some, S.; Ray, J. K.; Banwell, M. G.; Jones, M. T., New protocols for the synthesis of 3,4-annulated and 4-substituted quinolines from $\beta$-bromo- $\alpha, \beta$-unsaturated aldehydes and 1-bromo-2-nitrobenzene or 2-bromoacetanilide. Tetrahedron Letters 2007, 48 (20), 3609-3612.

43. Paul, S.; Samanta, S.; Ray, J. K., Palladium-catalyzed one-pot Suzuki coupling followed by arylpalladium addition to aldehyde: a convenient route to fluoren-9-one derivatives. Tetrahedron Letters 2010, 51 (42), 5604-5608.

44. Jana, R.; Paul, S.; Biswas, A.; Ray, J. K., Copper-catalyzed addition of water affording highly substituted furan and unusual formation of naphthofuran ring from 3-(1alkenyl)-2-alkene-1-al. Tetrahedron Letters 2010, 51 (2), 273-276.

45. Ramesh, D.; Kar, G. K.; Chatterjee, B. G.; Ray, J. K., Studies on polycyclic azaarenes. 2. Synthesis of trans-3,4-dihydroxy-3,4-dihydrobenz[c]acridine and trans-8,9dihydroxy-8,9-dihydrobenz[c]acridine. The Journal of Organic Chemistry 1988, 53 (1), 212-214.

46. Ray, D.; Ray, J. K., Novel Synthetic Approach Toward ( \pm )- $\beta$-Cuparenone via Palladium-Catalyzed Tandem Heck Cyclization of 1-Bromo-5-methyl-1-aryl-hexa-1,5dien-3-ol Derivatives. Organic Letters 2007, 9 (2), 191-194.

47. Goswami, S.; Mukherjee, R.; Ray, J., Design and Synthesis of a Neutral Fluorescent Macrocyclic Receptor for the Recognition of Urea in Chloroform. Organic Letters 2005, 7 (7), 1283-1285.

48. Roy, B. C.; Gupta, M. D.; Bhowmik, L.; Ray, J. K., Synthesis and characterization of poly $(2,5$-dimethoxyaniline) and poly (aniline-Co-2, 5- 
dimethoxyaniline): The processable conducting polymers. Bulletin of Materials Science 2001, 24 (4), 389-396.

49. Roy, B. C.; Gupta, M. D.; Bhowmik, L.; Ray, J. K., Synthesis and characterization of poly(2,5-dimethoxyaniline) and poly(aniline-Co-2,5dimethoxyaniline): The processable conducting polymers. Bulletin of Materials Science 2001, 24 (4), 389-396.

50. Nandi, S.; Ray, J. K., Palladium-catalyzed cyclization/cyclopropanation reaction for the synthesis of fused N-containing heterocycles. Tetrahedron Letters 2009, 50 (50), 6993-6997.

51. Davis, F. A.; Ray, J. K.; Kasperowicz, S.; Przeslawski, R. M.; Durst, H. D., .beta.-(N,N-Dialkylamino)ethyl arylthiosulfonates: new simulants for O-ethyl S-[2(diisopropylamino)ethyl] methylphosphonothioate. The Journal of Organic Chemistry 1992, 57 (9), 2594-2599. 